\title{
APUNTES SOBRE LA INSTITUCIÓN DEL JURADO EN ESPAÑA: EL JURADO EN EL SIGLO XIX
}

\author{
María del Carmen SÁENZ BERCEO \\ Profesora Titular DE Historia DEL DERECHO \\ UNIVERSIDAD DE LA RIOJA
}

PONENCIA PRESENTADA EN LAS «JORNADAS DE ESTUDIO SOBRE EL JURADO»

ORGANIZADAS POR EL ÁREA DE DERECHO PROCESAL DE LA UR

SALÓN DE GRADOS DEL EDIFICIO QUINTILIANO (UNIVERSIDAD DE LA RIOJA).

LOGROÑO, I8 Y I9 DE MAYO DE 2006.

s $u$ m a r i o

I. Introducción. 2. Reconocimiento del Jurado: el Estatuto de Bayona. 3. El Jurado de Cádiz. 4. La Constitución de I837 y el Jurado. 5. El Jurado desde la caída de Espartero a la Revolución de septiembre de i868. 6. «La Gloriosa»: inicio del triunfo del Jurado en nuestro derecho. 7. Ascenso y caída de la institución del Jurado.

\section{Introducción.}

El pasado mayo, y al objeto de estudiar la nueva Ley del Jurado, se celebraron en la Universidad de La Rioja unas jornadas sobre esta institución. En ellas corrió de mi mano el realizar una breve semblanza histórica de una institución tan importante y a la vez tan controvertida como el Jurado.

Fruto de aquellas reflexiones es este trabajo que tiene como objeto poner de relieve, de una forma breve, cómo se introdujo el Jurado en nuestro derecho y los avatares por los que pasó la institución hasta su desarrollo y consolidación con la primera Ley sobre el Jurado, propiamente dicha, a finales del siglo XIX, concretamente en I888. 
No voy a retrotraerme a figuras muy antiguas. Solamente citaré, por ser ya clásico en la doctrina, algunos textos medievales que recogen instituciones, que en cierto modo, podrían considerarse como precedentes del Jurado, como son el Fuero Juzgo, el Fuero de Escalona', Les Costums de Tortosa, o el mismo Tribunal de las Aguas de Valencia donde los conflictos entre regantes se resolvían con la participación directa de los campesinos de la cuenca del Turia y el fallo era inapelable, si bien, creo que la institución del Jurado, tal y como se concibe ahora, y se concebía en el siglo XIX, no tiene mucho entronque en nuestra tradición jurídica.

Por todo ello, el Jurado de cuya evolución voy a ocuparme es aquel que surge en el siglo XIX, cuando la situación social y política permiten que se hagan realidad, o al menos que comiencen a ser consideradas como viables, instituciones que como la del Jurado, están en el acervo común de todos los liberales. Es por esta razón, por estar vinculado al pensamiento liberal, a los que aman la libertad y el progreso, por lo que en nuestro país la institución seguirá, en cuanto a su reconocimiento y vigencia, los vaivenes, los avances y retrocesos comunes al movimiento social, político y constitucional que se desarrolla a lo largo del siglo XIX, como ha sido puesto de relieve en varias ocasiones. La Ley Orgánica del Tribunal del Jurado, señala: «Lo que puede considerarse una constante en la historia del derecho constitucional español; cada período de libertad ha significado la consagración del Jurado; así en la Constitución de Cádiz de I8I2, y en las de I837, I869 y I93I, y por el contrario cada época de retroceso de las libertades públicas ha eliminado o restringido considerablemente ese instrumento de participación ciudadana, en paralelo y como complemento a las restricciones del conjunto de sus derechos y de los instrumentos de participación en los asuntos públicos»².

Cuando en el siglo XIX se plantea el asunto de la conveniencia del Jurado, se está pensando en un órgano, en una institución, que permita la participación ciudadana en la administración de justicia para garantizar la correcta aplicación de la Ley, y por ende, la obtención de resoluciones más justas, y sobre todo porque se concibe el Jurado como exponente, manifestación y garantía de una libertad que incesantemente se está demandando. No voy a centrarme por tanto, porque creo que no es objeto de este trabajo, en si el Jurado que se organiza se parece a la institución del escabinado, al modelo anglosajón o a otros.

Se tenía certeza, o al menos era un sentimiento extendido, que los jueces tradicionales no eran imparciales, por ello el ser juzgado por iguales, el Jurado, era para nuestros intelectuales y legisladores decimonónicos requisito y consecuencia a la vez del ejercicio de la libertad, de ahí que el primer ámbito donde se implanta y como tal ejerce es en los delitos contra la libertad de imprenta, contra lo que ahora denominamos libertad de expresión.

¿Por qué fue en esa esfera donde se materializa la institución por primera vez? No fue algo casual. Se consideraba que la libertad de expresión, la libertad de imprenta, era imprescindible para conocer, para saber, y en esa medida, para hacer ciudadanos más sabios, más responsables, participativos, y en definitiva, más libres. «La libertad de la imprenta, la libre discusión sobre materias de gobierno, la circulación de obras y tratados de derecho público y la jurisprudencia, de que hasta ahora había carecido España, serán el

\footnotetext{
${ }^{\text {I }}$ El Fuero establece que cuatro ciudadanos escogidos entre los más nobles y sabios administren justicia permanente con el juez. Realmente no es un Jurado en el sentido actual, ayudaban al juez en su misión y en ocasiones podían estar tanto o más preparados en asuntos de derecho que el propio juez, con lo que su similitud con el Jurado moderno es lejana, destacable como precedente pero nada más. Lo mismo los diez hombres que juzgaban con el juez y que recogía el Fuero de Toledo.

${ }^{2}$ Exposición de motivos: Ley Orgánica 5/I995, de 22 de mayo, del Tribunal del Jurado.
} 
verdadero y proporcionado vehículo que lleve a todas las partes del cuerpo político el alimento de la Ilustración»³.

España venía de fuertes medidas de censura que se habían intensificado a raíz de la Revolución Francesa, y que habían hecho que mentes tan claras y en cierto modo avanzadas como Floridablanca, trataran a toda costa de evitar que las ideas consideradas subversivas y altamente peligrosas para el país, que estaban triunfando en Francia, se propagasen en la madre patria, y para ello se había establecido un tremendo control sobre todo lo que venía de fuera. Los órganos encargados de administrar justicia no eran ajenos a esa idea, a esa política, por ello se busca enseguida instituir el Jurado como institución que al estar formada por distintas personas que no eran profesionales de la justicia pudiera, al ser más independiente, garantizar la libertad de expresión tan importante siempre, pero más en esos tiempos de profundos cambios en busca de la senda de la modernidad.

2. Reconocimiento del Jurado: el Estatuto de Bayona.

Como en otros ámbitos o instituciones ${ }^{4}$, es el Estatuto de Bayona el primer texto que hace referencia al Jurado en nuestra historia del derecho. Conocido es su artículo io $6^{5}$, el cual recoge en primer lugar la publicidad del proceso penal y conjuntamente dispone que: «En las primeras Cortes se tratará de si se establecerá o no el proceso por Jurados».

Este artículo tiene importancia por ser el primero que se ocupa del Jurado, que al menos lo plantea como posibilidad, si bien en el ámbito práctico no tuvo ninguna efectividad dado que ni siquiera lo recoge como norma sino que tan sólo establece la posibilidad de que las Cortes se ocupen de ello, y decidan en definitiva la conveniencia o inconveniencia del establecimiento de la institución.

Por otra parte, el procedimiento de elaboración y aprobación del Estatuto de Bayona, y su consideración de Carta Otorgada, y en cierto modo impuesta por el odiado emperador de los franceses, llevará a su rechazo absoluto como norma genuinamente española y para españoles ${ }^{6}$. A ello se unió el que por estar inmersos en el grave conflicto bélico que nos enfrentaba con Francia el Estatuto de Bayona no tuvo virtualidad práctica a considerar y el texto, como es lógico, quedó arrumbado a medida que los españoles conseguían derrotar y desplazar hacia el Norte a las tropas francesas.

\footnotetext{
${ }^{3}$ Discurso preliminar a la Constitución de I8I2.

${ }^{4}$ Así ocurre por ejemplo con la unidad de Códigos, referente a lo cual ya el Estatuto de Bayona establece: «Las Españas y las Indias se gobernarán por un solo Código de leyes civiles y criminales». Artículo 96.

«Habrá un solo código de Comercio para España e Indias». Artículo iız.

${ }^{5}$ Con ello Napoleón no hizo sino seguir las sugerencias de los que participaron en la Asamblea de Bayona que discutió el Proyecto de Constitución para España. El Proyecto, inspirado en la Constitución francesa, recogía en su artículo 6r la Institución del Jurado. La junta reunida en Bayona no era partidaria de la introducción del Jurado y se inclinó por su suspensión y por recomendar que en esta materia fuese el Consejo de Estado quien propusiera a las Cortes lo que creyera más oportuno. GUTIERrez SANZ, M.R., El Jurado: aproximación a su sentido histórico y actual, pág. 62. Barcelona, I99I.

${ }^{6}$ El planteamiento que recoge el artículo so6 respecto a la institución del Jurado, tiene su inspiración inmediata en el artículo 62 de la Constitución Francesa napoleónica.
} 


\section{El Jurado en Cádiz.}

Las siguientes Cortes que hubieran podido tratar y desarrollar lo estipulado en el artículo ro6 del Estatuto de Bayona fueron las Cortes de Cádiz, que comenzaron sus sesiones el 24 de septiembre de I8ıо, y que aunque deseaban ver implantado el Jurado, guiadas por la prudencia, y considerando que la sociedad española no estaba preparada para ello, decidieron posponerlo para más adelante, como hiciera la norma de Bayona. El Discurso Preliminar de la Comisión lo explicita de forma clara. Considera que la institución del Jurado es deseable pero teniendo en cuenta asimismo que la sociedad española no está preparada para ello, no desea violentarla e «imponerle» una institución que entonces no daría sus frutos, sino con la que se conseguiría todo lo contrario a lo pretendido, así dice al respecto:

La Comisión «se ha abstenido de introducir una alteración substancial en el modo de // administrar la justicia, convencida de que reformas de esta trascendencia han de ser el fruto de la meditación, del exâmen mas prolixo y detenido, único medio de preparar la opinión pública para que reciba sin violencia las grandes innovaciones. Pero al mismo tiempo la Comision ha creido que la Constitución devia dexar abierta la puerta para que las Cortes sucesivas, aprovechándose de la experiencia, del adelantamiento, que ha de ser consiguiente al progreso de las luces, puedan hacer las mejoras que se estimen oportunas en el importantísimo punto de administrar justicia»?

Como ya ocurriera con la propia Constitución, la Comisión tiene gran cuidado de fundamentar el Jurado en nuestras antiguas Leyes, aún admitiendo que la similitud no es total, y recurre también como fuente de la que bebe la institución a lo establecido por el derecho inglés, considerado en la época el más avanzado y justo, y huyendo desde luego, de relacionarlo con ninguna institución, por lejana que fuera, del acervo jurídico francés ${ }^{8}$.

La prudencia, y sobre todo los temores de los diputados gaditanos dieron como fruto el artículo 307 de la Constitución de ı8ı2 que establece: «Si con el tiempo creyesen las Cortes que conviene haya distinción entre los jueces del hecho y del derecho, la establecerán en la forma que juzguen conducente»?

7 Discurso Preliminar a la Constitución de Cádiz, págs. 6o y 6I. Clásicos en la Biblioteca Nacional. Edición digital. Biblioteca virtual Miguel de Cervantes.

8 Aunque la influencia no es despreciable pues ya la Constitución francesa de I79I recogía el Jurado: «Les jurés que déclareront le fait, ne pourront être au-dessous du nombre de douze». Artículo 9.

${ }^{9}$ Me parece interesante recoger el razonamiento de la Comisión con respecto a la institución del Jurado porque nos permite conocer qué significaba el Jurado para nuestros legisladores decimonónicos y sus «temores» a implantar la institución, que si no resultaba adecuada podía conducirla al fracaso más rotundo, por ello va trascrito tal cual figura en el original: «La Comision dexa insinuado en otra parte la conveniencia que resultaria de perfeccionar la administración de justicia, separando las funciones que exercen los jueces en fallar á un mismo tiempo sobre el hecho y el derecho. Mas al paso que no duda que algun dia se establezca entre nosotros la saludable y liberal institución de que los españoles puedan terminar sus diferencias por jueces elegidos de entre sus iguales, en quienes no tengan que temer la perpetuidad de sus destinos, el espíritu de cuerpo de tribunales colegiados, y en fin el nombramiento del Gobierno, cuyo influxo no puede menos de alejar la confianza por la poderosa autoridad de que está revestido, reconoce la imposibilidad de plantear por ahora el método conocido con el nombre de juicio de Jurados. Este admirable sistema, que tantos bienes produce en Inglaterra, es poco conocido en España. Su modo de enjuiciar es del todo diferente del que se usa entre nosotros; y hacer una revolucion total en el punto mas difícil, mas trascendental y arriesgado de una // legislación, no es obra que pueda emprenderse entre los apuros y agitaciones de una convulsion política. Ni el espíritu público, ni la opinión general de la Nacion

Redur 4 / 2006 
En el Proyecto era el artículo 305 el que recogía la institución del Jurado, que pasó con un contenido exacto al que constituyó el artículo 307 que hemos trascrito. En la discusión parlamentaria intervinieron los señores José Martínez, Muñoz Torrero, Golfín y Argüelles. Fue la sesión del iz de diciembre de i8ıı.

El Sr. Martínez propuso que se suprimiera el artículo pues era un mero consejo y no un precepto lo que se recogía en él. Muñoz Torrero discrepó de ello señalando que la Comisión creía conveniente, e incluso necesario, declarar esa facultad de las Cortes sucesivas y que el consejo no era nuevo «sino una declaración positiva de las facultades que acerca de este particular deben tener las futuras Cortes» ${ }^{\mathrm{IO}}$.

El Sr. Golfín fue más lejos. En su opinión el artículo debía ponerse en tono imperativo «de modo que sea un verdadero precepto» e incluso sugirió un cambio de redacción. Por fin el Sr. Argüelles, conciliador como solía ser, y convencido de que no era el momento adecuado, dijo que la Comisión no quería imponer nada y creyó suficiente «quitar las trabas a las futuras Cortes, autorizándolas por la misma Constitución para hacer esta novedad en el sistema judicial en beneficio de los ciudadanos españoles. Con esto solo ellos tendrán buen cuidado de no dejar pasar la primera ocasión oportuna que se les presente de mejorar tan notablemente la felicidad de la Nación». Después de la intervención del Sr. Argüelles el artículo se aprobó como estaba redactado constituyendo el artículo 307 de la Carta Magna ${ }^{\mathrm{II}}$.

pueden estar dispuestos en el dia para recibir sin violencia una novedad tan substancial. La libertad de la imprenta, la libre discusión sobre materias de gobierno, la circulación de obras y tratados de derecho público y jurisprudencia, de que hasta ahora había carecido España, serán el verdadero y proporcionado vehículo que lleve á todas las partes del cuerpo político el alimento de la ilustración, asimilándole al estado y robustez de todos sus miembros. Por tanto la Comision ha creido que en vez de desagradar á unos é irritar á otros con una discusión prematura, ó acaso impertinente, debía dexar al progreso natural de las luces el establecimiento de un sistema, que solo puede ser útil quando sea fruto de la demostración y del convencimiento. Por eso dexa á las Cortes sucesivas la facultad de hacer en este punto las mejoras que crean convenientes. Mas al mismo tiempo no puede menos de indicar que el método de juzgar por Jurados no solo no fue desconocido por nuestras antiguas leyes, como se vé por la siguiente cláusula del fuero municipal de Toledo que dice: //

'Todos sus juicios dellos sean juzgados, según el Fuero Juzgo, ante diez de sus mejores, é mas nobles, é mas sabios dellos, que sean siempre con el alcalde de la ciudad'; sino que aun hoy dia está de cierto modo en práctica en algunas provincias del reyno. En la isla de Iviza y Formentera el asesor nombrado por el Gobierno no puede por sí solo sentenciar pleyto alguno sin la concurrencia de dos ó mas hombres, que pueden llegar hasta el número de seis, tomados de todos estados. Esta institución, aunque no es en rigor idéntica en todos sus trámites á los Jurados de Inglaterra, está indudablemente fundada sobre los mismos principios. Y la insaculacion que en Iviza se hace de un número proporcionado de vecinos para sacar de entre ellos los que acompañan al asesor, y los que con el título de prohombres eligen las partes para concurrir con el juez delegado en la apelación, el qual tambien ha de ser natural y vecino del pais, no dexa duda sobre que el orígen de este método, tan liberal y justificado, viene del que se observaba en Roma antes de la tiranía de los Emperadores. El album judicum, Señor, de donde tomaban los ciudadadanos romanos los jueces de hecho, no puede ser desconocido de ninguno que // esté medianamente versado en la jurisprudencia antigua de Roma. Por lo mismo la Comision se cree en el caso de recomendar esta admirable institución de una provincia del reyno, para que el Congreso no desconozca un método que tal vez convendrá algun dia generalizarlo á todas las demas».

Discurso Preliminar a la Constitución de Cádiz, págs. 88-91.

Io Diario de Sesiones de las Cortes Generales y Extraordinarias (en adelante D.S.): dieron principio el 24 de septiembre de I8Io y terminaron el 20 de septiembre de I8I3. Madrid. Imprenta de J.A. García, I870-I874, Vol. IV, pág. 2420.

${ }^{\text {II }}$ Ídem. 
La prudencia de las Cortes en su formulación de la institución del Jurado quedó patente, pero quizá no hubiera sido necesaria pues todo el articulado de la Constitución apenas entró en vigor dado que la vuelta de Fernando VII después de la firma del Tratado de Valençay, supuso la ruina de la Constitución y de la obra de las Cortes de Cádiz, pues como es sabido su Decreto de 4 de mayo en I8I4 dejó sin efecto y sin ningún valor lo establecido hasta entonces, y por ende las Cortes no tuvieron opción de desarrollar lo estipulado en el artículo 307 de la Constitución.

La vuelta a la Constitucionalidad de I8I2 vino de la mano del triunfante alzamiento del Teniente Coronel Rafael del Riego en Cabezas de San Juan cuando se iniciaba I820. El triunfo de Riego significó la vuelta a la Constitución, y como es lógico, también al deseo de contar con los jueces de hecho, con el Jurado. Más madura la sociedad española, el Jurado verá por fin la luz, aunque eso si, limitado a intervenir en los delitos por «abuso» de la libertad de expresión, en los delitos de imprenta, siguiendo en ello la estela marcada por los constitucionalistas doceañistas ${ }^{\mathrm{I2}}$.

El Decreto de 22 de Octubre, por el que se aprueba el reglamento sobre libertad de imprenta, recoge la competencia de los jueces de hecho en el enjuiciamiento de los delitos cometidos por abusar de la libertad de imprenta. El título VII «del modo de proceder en estos juicios» recoge en I9 artículos, del 36 al 74, todo lo referente a los jueces de hecho y sus actuaciones. Los elegidos habían de ser ciudadanos mayores de 25 años, en el ejercicio de sus derechos ${ }^{\mathrm{I} 3}$. Servir el cargo era obligatorio y se renovaba cada año.

Uno de los alcaldes constitucionales elegía nueve jueces de hecho, y ante el alcalde prestaban el siguiente juramento: «Juráis haberos bien y fielmente en el cargo que se os confía, decidiendo con imparcialidad y justicia en vista del impreso y denuncia que se os va a presentar, si ha o no lugar a la formación de la causa?». Estos nueve jueces de hecho componían el Jurado de acusación, que a la vista del escrito u obra sometida a su consideración debía determinar si había o no había lugar a la formación de causa. Si la respuesta era afirmativa se remitía todo al juez, que debía actuar según lo estipulado. El

I2 El Decreto de las Cortes de Cádiz, de io de noviembre de $I 8$ Io, sobre libertad política de la imprenta, remitía la resolución de estos delitos a los jueces y tribunales ordinarios. Todavía no establece el Jurado, pero si introduce, en mi opinión, un órgano que podemos considerar como de apoyo a la justicia, y que dado su cometido y composición, se aproximaría en cierto modo al Jurado. El órgano en cuestión es el denominado como Junta de Censura, tanto suprema como provincial. Decía el artículo I3 del Decreto: «Para asegurar la libertad de la Imprenta, y contener al mismo tiempo su abuso, las Cortes nombrarán una Junta Suprema de Censura, ... compuesta de nueve individuos, y á propuesta de ellos otra semejante en cada capital de provincia compuesta de cinco». El articulo i4 detallaba la calidad de los designados que habían de ser «eclesiásticos tres de los individuos de la Junta Suprema de Censura, y dos de los cinco de las Juntas de las provincias, y los demás serán seculares, y unos y otros sujetos instruidos, y que tengan virtud, probidad y talento necesario para el grave encargo que se les encomienda». Por fin el artículo i5 establecía su cometido: «Será de su cargo examinar las obras que se hayan denunciado al poder ejecutivo ó Justicias respectivas; y si la Junta censoria de provincia juzgase fundado su dictamen, que deben ser detenidas, lo harán así los Jueces, y recogerán los ejemplares vendidos». GÓMEZ-REINO Y CARNOTA, E., Aproximación histórica al derecho de la imprenta y de la prensa en España (I480-I966), págs. 239-24I. Madrid I977.

El Decreto de Io de junio de 1813 , sobre adiciones a la Ley de libertad de imprenta, matizaba claramente que los miembros de las Juntas de Censura habían de ser «legos», habían de ser jueces de hecho y así no podían ser miembros de ellas «los Prelados eclesiásticos, los Magistrados y Jueces, ni otra persona que ejerza jurisdicción civil ni eclesiástica». Artículo 3. Ibídem, págs. 245-249.

${ }^{13}$ Estaban excluidos, según el artículo 40: «los que ejerzan jurisdicción civil o eclesiástica, los Gefes políticos, los Intendentes, los Comandantes Generales de las armas, los Secretarios del Despacho, y los empleados en sus secretarías, los Consejeros de Estado, y los empleados en la servidumbre de Palacio».

Redur 4 / 2006 
Jurado de calificación estaba compuesto por siete jueces de hecho, nombrados también por sorteo, ante el cual, y presidido por el juez, se desarrollará el juicio en Audiencia pública ${ }^{\mathrm{I}}$.

El Decreto de I2 de febrero de I822: Ley adicional a la de 22 de octubre de I820 sobre la libertad de imprenta, vendrá a completar lo regulado en aquella, y por lo que se refiere a los jueces de hecho, los artículos II al i4 tratan de subsanar errores advertidos o actuaciones dificultosas, de manera que la actuación de los jueces de hecho fuera más clara y sencilla.

El tribunal del Jurado mereció la atención de los codificadores de esta etapa. El Código penal de I 822 se ocupaba del Jurado en los artículos Io4 y IIo. Por su parte el Proyecto de Código procesal criminal de I823 reconocía la competencia del Jurado en el conocimiento de los delitos graves, con algunas excepciones, y establecía un doble Jurado de acusación y de calificación.

La entrada en España de los Cien Mil hijos de San Luis, en cumplimiento del Tratado de Verona, supondrá la reposición de todas sus prerrogativas como Rey absolutista a Fernando VII, y como ocurriera cuando éste regresó de Francia, su Decreto de I de octubre de 1823 dejó sin efecto y sin ningún valor tanto la Constitución de Cádiz como la serie de Leyes, Decretos, etc. que se habían promulgado desde el triunfo de Riego. Como en la anterior ocasión, persecuciones, deportaciones y vuelta a la más rancia tradición se impusieron en España hasta su muerte, y por supuesto lo establecido para la actuación de los jueces de hecho quedó totalmente anulado.

\section{La Constitución de I837 y el Jurado.}

La siguiente etapa en la que vuelve a contemplarse la intervención de los jueces de hecho, del Jurado, coincide, tal y como señalábamos al principio, con una etapa de libertades que supondrá la elaboración y aprobación de la Constitución de I837, después de un pequeño intervalo en el que se resucitó la Constitución del I2, y se puso de nuevo en vigor la Ley de Imprenta de I820.

La Constitución de I837, en lo que se refiere a la institución del Jurado, sigue la misma línea cauta del Estatuto de Bayona y de la Constitución de I8I2, y a decir verdad no se ocupa con mucho detalle de la institución.

Su artículo 2 repone la libertad de imprenta para todos los españoles y señala que la calificación de los delitos de imprenta corresponde con carácter exclusivo a los Jurados, lo que creo es digno de destacar pues está manifestando su desconfianza en los jueces profesionales y atribuyendo a los jueces de hecho la facultad de determinar, en la práctica, la existencia de delito. Ya establecía la Ley de 1820 el Jurado de Calificación, pero ahora la Constitución parece querer destacarlo al establecer que le corresponde «en exclusiva» determinar si los hechos denunciados tienen entidad suficiente para iniciar el proceso. En realidad, este artículo se ocupa de restablecer la libertad de imprenta, considerada de extrema importancia, y recoge el Jurado como institución ligada a la defensa de esa libertad pero desde luego no lo generaliza a otro tipo de delitos.

Cuando la Constitución se ocupa del Jurado propiamente dicho, lo hace en un lugar mucho menos relevante, fuera del articulado, en una adicional que estipula: «Las

${ }^{\text {I4 }}$ Con determinados requisitos y con causa determinada, se componía un segundo Jurado de calificación compuesto de doce miembros, elegidos también por sorteo.

Redur 4 / 2006 
leyes determinarán la época y el modo en que se ha de establecer el Juicio por Jurados para toda clase de delitos». Si bien es verdad, que ya se hace alusión a la institución del Jurado para todo tipo de delitos y ello sí que me parece significativo, aunque en la línea seguida por los Constituyentes, ajustándose a las bases elaboradas por la Comisión, se dejó para el desarrollo legislativo general todo aquello que aún siendo importante, se consideraba que debía salir del texto constitucional al objeto de construir un edificio más ligero que la Constitución de ı8ı2, y ello se hizo con esta institución.

La discusión parlamentaria de esa adicional, que tantas expectativas abría, se realizó el 27 de abril de I837, día del cumpleaños de la Reina. Nada más plantearse la discusión intervino el Sr. Vila haciendo notar lo rápido, la urgencia que parecía existir en concluir la Constitución, de manera que como este diputado pone en evidencia, se estaban aprobando artículos de gran importancia sin apenas discusión: «¿Quien pensara que en menos de dos horas se aprobasen nueve artículos constitucionales que envuelven cuestiones de la más alta importancia?» ${ }^{15}$.

Con referencia al Jurado señalaba: «Las naciones que han estimado en algo la libertad de sus ciudadanos, el honor y el deber de los miembros de la sociedad, han ocupado días enteros... ¿Y nosotros decidiremos sobre ello en pocos minutos? ${ }^{16}$ Insiste en que es un error gravísimo el pensar que en I837 España no está todavía preparada para admitir el Jurado, y como si no pudiera creerlo dice: «En I837, señores, en I837 ¿No se mandará en España establecer el Jurado? En la Constitución de I837 ¿No se verá una línea que consigne que se establece el Jurado?.

Siento señores el honor nacional humillado cuando apenas podemos salir de los límites de nuestras fronteras sin que pisemos el terreno de otra nación vecina en la que si delinquimos seremos juzgados por Jurados. ¿Y en España no ha venido el día de establecerlos? ¿Y los legisladores del año I837 ¿No los consignan en su Constitución? ¿Sabeis señores lo que vais a decretar? Que España es la más ignorante, la más desmoralizada de cuantas naciones la rodean. No tiene el juicio de Jurados».

«Los tiene la Francia, los tiene el Portugal, los tienen cuantas Naciones gozan del gobierno representativo: mas los legisladores del año I837 los niegan à la España. Señores, no los tendremos si este artículo se aprobase; la España de I837 no establece los Jurados.

Nos falta la instrucción, se nos dice; nos hallamos sin Códigos; tenemos una guerra civil que nos devora; no puede establecerse como no lo sea en todos los puntos» ${ }^{\text {17 }}$.

Reitera que se siente abandonado incluso de los que desean el Jurado, y que no busca gloria para sí sino la felicidad de la nación y que si «ंEra mayor la instrucción de los ingleses cuando lo establecieron? ¿Lo era la de la Francia? ¿Lo era la de Portugal, la de la Bélgica, la de los Estados Unidos?».

Con el mismo razonamiento rebate lo de que en España no hay Códigos y se pregunta si los tienen los otros. Va contradiciendo argumentos y deja claro que todos quieren terminar con las votaciones y dar por finalizada la discusión sobre la Constitución, pero él insiste en que el asunto es de gran trascendencia, aunque ya derrotado afirma: «se que me esfuerzo en vano, pero habrá al menos quien haya levantado la voz en este recinto...».

${ }^{15}$ D. S. de las Cortes Constituyentes. Dieron principio el I7 de Octubre de 1836 y terminaron el 4 de Noviembre de I837. Madrid. Imprenta de J. A. García. I870-I877, Vol. 5, pág. 3042.

${ }^{16}$ Ibídem, pág. 304I.

${ }^{17}$ Ibídem, pág. 3042.

Redur 4 / 2006 
Les dice a sus compañeros que reflexionen, que «La comision carga sobre si una gran responsabilidad: priva a la España inmediatamente del juicio de Jurados; marca en la Constitución de 1837 que no está en estado de recibirlos, y la desnivela de las demás Naciones que hoy día gozan de este beneficio». Cumplido su deber y tranquilizada su conciencia, el diputado se opuso a la adicional $\mathrm{I}^{\mathrm{a}}$.

Le contestó el diputado Sr. González insistiendo en que el asunto no era discutir la utilidad e importancia del Jurado, en la que más o menos coincidían, sino de oportunidad, pues dada la crítica situación de España, creían los miembros de la Comisión «que en la época presente no sería esta institución tan útil como podrá serlo en lo sucesivo».

Sin más discusión quedó aprobada la adicional $\mathrm{I}^{\mathrm{a}} \mathrm{y}$ por ende, el establecimiento del Jurado se remitió a otras Cortes venideras, y a otra mejor ocasión, como había ocurrido casi treinta años antes.

Intento de cumplimiento de esa disposición constitucional fue la Ley de I7 de octubre de I837, que sin embargo se quedó muy alejada del esperado Jurado para toda clase de delitos, ya que el Jurado que se recoge en ella entiende tan solo de los delitos de imprenta configurándose, como había venido siendo habitual, en la doble vertiente de Jurado de Acusación y Jurado de Calificación. La Ley actualiza en cierto modo las de la década de los veinte y establece la normativa de la actuación del Jurado en los artículos 4 al 8, ambos inclusive, estableciendo que los jueces darán su veredicto de forma secreta, actuando su presidente como portavoz que comunicará el resultado. Regula también el número y composición del Jurado y estable las condiciones necesarias, principalmente económicas, para formar parte de él.

5. El Jurado desde la caída de Espartero a la Revolución de septiembre de i868.

La etapa moderada, que comenzará con la caída de Espartero, está sustentada por una ideología más conservadora, cuya influencia se dejará sentir lógicamente en la Constitución de 23 de mayo de I845, que en ningún momento recoge la institución del Jurado. Sin embargo la Constitución recoge la libertad de imprenta y establece en su artículo 2: «Todos los españoles pueden imprimir y publicar libremente sus ideas sin previa censura, con sujeción a las leyes». Recoge la formulación clásica de esta libertad y mantiene el Jurado en los delitos de imprenta, como venía funcionando hasta entonces, dado que no deroga ni modifica el Real Decreto de io de abril de i844, aunque como veremos, no por mucho tiempo.

Acorde con la ideología imperante, más conservadora, se señala que por el simple hecho de contar con un Jurado, con jueces legos, no se puede afirmar que las resoluciones sean más justas. Por ello el Real Decreto de Io de abril de I844 sobre reforma de la legislación de imprenta, establecía ya claros límites a la posibilidad de formar parte del $\mathrm{Jurado}^{\mathrm{I} 8}$, límites que están basados tanto en la edad, 30 años, como en la posesión de bienes

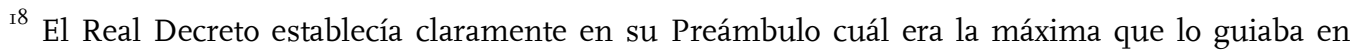
este punto y así decía que si las personas que lo componían no ofrecían «las condiciones de propiedad y de saber que son necesarias para asegurar el acierto y la independencia de los fallos, el juicio por Jurados en vez de ser una garantía de moderación y de imparcialidad en el delicado uso del derecho de emitir el pensamiento, se convierte en una ficción tanto más funesta cuanto que tiende a dejar impunes los delitos conservando las formas y las apariencias legales. No son los proletarios y los ignorantes los que pueden ser jueces en las graves cuestiones que la imprenta suscita, y triste y

Redur 4 / 2006 
suficientes y de cultura o preparación también suficientes, indudablemente buscando mayor madurez y mayor posibilidad de discernimiento y de justicia, que para los hombres de la época sólo las daban la posesión de bienes materiales o la posesión de una educación e instrucción suficientes ${ }^{\mathrm{I}}$.

Este Decreto apenas tuvo vigencia un año, ya que el 6 de julio de I845 un Real Decreto modifica el de abril de i844 y suprime el Jurado al establecer en su artículo 4 que: «La calificación de los delitos de imprenta y la aplicación de la pena se harán en lo sucesivo por un tribunal compuesto de cinco jueces de primera instancia y de un magistrado presidente» ${ }^{20}$.

El Jurado vuelve a contemplarse en la legislación española, de nuevo solamente para delitos de imprenta, gracias al Decreto de 2 de abril de I852, cuyo Proyecto, elaborado y presentado a la Reina por Juan Bravo Murillo, limita la posibilidad de formar parte de los jueces de hecho a aquellos que estén incluidos en la lista de contribuyentes, en concordancia con la idea contenida en la exposición de motivos que el mismo Bravo Murillo presenta, y donde se especifica que «para la formación de este Tribunal, que ha de ser el juez de los delitos justiciables, principalmente de la opinión, se ha creído necesario ... buscar sólo la garantía en la propiedad, como la más interesada a la vez en la salvaguardia y en el verdadero progreso» ${ }^{2 \mathrm{I}}$. También se limitan los asuntos en los que el Jurado puede intervenir, pues tal y como establece el artículo 46 , corresponden al conocimiento del Jurado:

1. Los delitos contra el orden público.

2. Los delitos contra la sociedad.

3. Los delitos contra la autoridad, fuera de los casos determinados en el artículo $3 \mathrm{I}^{22}$.

Claro que este Decreto apenas si tuvo virtualidad, pues otro dado el 2 de enero de I853 introdujo modificaciones en el mismo y por lo que al Jurado compete establece en su artículo 7 que: «un tribunal de jueces de primera instancia, organizado de la manera que se dirá más adelante, conocerá de todos los delitos de imprenta, con excepción de los cometidos contra particulares y salvas las restricciones que contiene el artículo 5 de este Real Decreto» ${ }^{23}$.

En realidad este Decreto no hace sino volver a la legalidad que disponía el de I845, vuelta que es solicitada por el Consejo de Ministros a la Reina, a quien exponen cómo había funcionado y por qué había fracasado el Jurado establecido por los Decretos de I844 y

desastroso fuera su porvenir si bajo tan débil amparo se acogiese». Vilata MenAdes, S. Sobre el Jurado: un análisis desde una perspectiva distinta, págs. 74 y 75 . Valencia, 200I.

I9 El Título VIII del Decreto, «De la organización del Jurado» establece minuciosamente las condiciones, requisitos, exenciones... para ser juez de hecho. Los títulos IX y X recogen el procedimiento a seguir hasta la obtención de la sentencia. Comprenden los artículos 53 al 93.

${ }^{20}$ GÓmEZ-REINO Y CARNOTA, Aproximación histórica al derecho de la imprenta y de la prensa en España, págs. 30I-304.

${ }^{21}$ Real Decreto de 2 de abril de 1852 , reformando las disposiciones vigentes en materia de imprenta. Ibídem, págs. 304 y ss.

${ }^{22}$ El Título VII se ocupa del Jurado, en los artículos 63 al 94.

${ }^{23}$ Este Real Decreto derogaba, entre otros, los artículos 62 al 85, que componían prácticamente todo el título VII dedicado al Jurado.

Redur 4 / 2006 
$185^{24}$, señalando en contraposición, las virtudes del de 6 de julio de I845, que «ofrecía a la libertad, al orden y a la justicia reconocidas garantías de saber, de independencia y de imparcialidad en los fallos. Cualquiera que sea la opinión de la mayoría de los publicistas acerca del Jurado, es lo cierto que en España, en el estado actual de nuestras costumbres, inspira más confianza en el acierto de sus providencias un Tribunal de Jueces inamovibles e independientes que tienen por oficio administrar justicia, y fundan en administrarla bien su crédito, su reputación y su porvenir, que Jueces eventuales a quienes repugna abandonar sus ordinarias preocupaciones para contraer compromisos que juzgan graves y molestos» ${ }^{25}$.

El Jurado por lo tanto, excepto con ese breve intervalo de nueve meses, había desaparecido de la esfera jurídica española coincidiendo con la subida al poder de los moderados.

La Constitución de I856 remitía a las Cortes el tiempo y la forma de establecer el Jurado, como ya hicieran las primeras Constituciones, a la vez que contemplaba la competencia de la institución para toda clase de delitos, no tan sólo para los de imprenta, ${ }^{26}$ lo que representaba un gran avance si lo comparamos con la Constitución vigente y la legislación desarrollada al respecto en toda la etapa precedente. Sin embargo ello quedó solamente en buenas intenciones, pues como es sabido la Constitución de 1856 nunca fue promulgada. En esto, como en otros aspectos, la Constitución recogía avances significativos, y aunque no entró en vigor, supuso un interesante precedente de forma que en adelante, cuando se discutía o se reclamaba el reconocimiento de la institución del Jurado, ésta ya no se constreñía a los delitos de imprenta sino que se quería un Jurado «para toda clase de delitos», como había establecido la non nata.

Retomando la línea anterior, el Real Decreto de 15 de septiembre de 1856 por el que se aprueba el Acta Adicional a la Constitución de la Monarquía Española, dispone en su artículo $\mathrm{I}^{\mathrm{O}}$ : «La calificación de los delitos de imprenta corresponde a los Jurados, salvo las excepciones que determinen las leyes». Pero tampoco esta vez la institución del Jurado, aún estando reducida a la calificación de los delitos de imprenta, gozará de longevidad pues por la Ley de Imprenta de 13 de julio de 1857 , «un tribunal de Jueces de primera instancia, organizado con arreglo a lo que se dispone en el artículo siguiente, conocerá de todos los delitos de imprenta» (Artículo 37). Si bien, incluso antes había desaparecido de nuestra legislación, pues un Real Decreto de I4 octubre del mismo año I856, apenas un mes después de ser aprobada, había dejado sin efecto el Acta Adicional.

${ }^{24}$ Al respecto dicen: «Los Consejeros de la Corona que propusieron a V. M. el Real Decreto de io de abril de i844 hubieron de creer tal vez que si el Jurado no se había aplicado en España con éxito tan feliz como en otras naciones, sus inconvenientes no provenían de las circunstancias especiales de nuestro país, sino de haberse organizado sobre bases excesivamente democráticas. Con el Decreto referido se dio una forma mucho más restrictiva y conveniente a esta institución, y sin embargo, en I845 desapareció de la Ley fundamental porque las Cortes y V. M. la consideraron en desacuerdo con nuestras costumbres y con el modo de enjuiciar de nuestros Tribunales, y desapareció también de la Ley de imprenta, reemplazándola con Tribunales colegiados no permanentes de Jueces de primera instancia. Recientemente, y tal vez con la mira de completar con una nueva prueba las experiencias anteriores, se ensayó de nuevo el restablecimiento del Jurado en el Real Decreto vigente de 2 de abril del año anterior, y este ensayo ha sido un testimonio más de las dificultades que hay que vencer en España para naturalizar una institución desconocida». GÓMEZ-REINO Y CARNOTA, Aproximación histórica al derecho de la imprenta y de la prensa en España, pág. 324.

${ }^{25}$ Ídem.

${ }^{26} \mathrm{Su}$ artículo 73 disponía: «Las leyes determinarán la época y el modo en que ha de establecerse el juicio por Jurados para toda clase de delitos, y cuantas garantías sean eficaces para impedir los atentados contra la seguridad individual de los españoles».

Redur 4 / 2006 
Y siguiendo con los vaivenes que se producían en el ámbito ideológico y político una nueva Ley de imprenta, de talante más abierto, tratará de aunar la existencia de jueces profesionales y de hecho en los delitos de ese tipo. La Ley de Imprenta de 22 de junio de I864, modifica la de I857 en varios artículos. Por lo que a nuestro tema interesa, los nuevos artículos 38 y 39 establecen los Jueces de Imprenta, pero acompañados de un cuerpo de Jurados elegidos de entre los mayores contribuyentes de la tierra, la industria o el comercio; de los miembros más antiguos y que paguen más alta cuota de las Reales Academias o de los Abogados que paguen más cuota al Colegio de Abogados. Se amplía el arco social de donde pueden provenir los jueces de hecho respecto a lo recogido en I852 si bien es el matiz económico el que prima. La edad para ser jurado se rebaja y queda establecida en 28 años. (Artículos 40 y ss.) El desempeño del cargo de jurado, era obligatorio, como venía siendo habitual, salvo excepciones, y la asistencia a las sesiones también, pudiendo ser multados con una fuerte cantidad, 500 a 2000 reales, si no acudían a ellas sin justa causa.

La Ley terminaba con un artículo transitorio que estipulaba que «mientras se organiza el Jurado, se conservará para los delitos especiales de imprenta el Tribunal de Jueces de primera instancia. Fuera de las funciones que le corresponden como JuezPresidente, el Juez de imprenta ejercerá desde luego todas las demás que se le confieren por la presente ley».

El Jurado al fin desaparecería también de los delitos de imprenta, y por tanto no tendría cabida en nuestro ordenamiento jurídico, en los últimos tiempos de vigencia de la Constitución de I845, con el Real Decreto de 7 de marzo de I867 con el que daba virtualidad la Reina al Proyecto de Ley sobre libertad de imprenta presentado por González Bravo unos meses antes de que triunfase la revolución de septiembre, «La Gloriosa». En él, su título VI «De los tribunales de imprenta» encarga de la instrucción de esos delitos a los Jueces de Primera instancia del fuero común, desapareciendo del articulado cualquier referencia a la institución del Jurado. Aquí concluirá esta etapa, con la desaparición de la participación ciudadana en la administración de la justicia ${ }^{27}$. Por tanto, y resumiendo, podemos decir que salvo brevísimos intervalos, mientras estuvo vigente la Constitución de I845, el Jurado no tuvo virtualidad en España. «La Gloriosa» marcó otro estilo y otra forma de ver las cosas, y sobre todo, de entender las libertades y derechos.

6. «La Gloriosa»: inicio del triunfo del Jurado en nuestro derecho.

Con el triunfo de la revolución de septiembre de i868, la Reina se ve obligada a exiliarse a Francia y se constituye un gobierno provisional en Madrid, presidido por Serrano y contando con el general Prim, verdadero artífice de la Revolución, como hombre fuerte en el Ministerio de la Guerra. En su programa de Conciliación, que el gobierno dirigió a los ciudadanos poco después del Manifiesto del 25 de Octubre, se incluían como bases la

${ }^{27}$ De poco sirvió lo acordado en la reunión de jurisconsultos de 29 de octubre de i863, en la que se encontraban representadas todas las escuelas y partidos políticos, y en la que, y con referencia al tema de cual sería el mejor sistema de procedimiento criminal para armonizar los derechos del acusado y los deberes de la justicia, concluyeron que «siendo la administración de justicia una función de estado, corresponde ejercerla a los ciudadanos por derecho propio, como elementos que entran directamente en la formación de aquel. Por tanto, el juicio por Jurado, es la única forma posible que respeta las prescripciones de la justicia, y el procedimiento oral y público, el medio directo adecuado de llegar al conocimiento del hecho». GUTIÉRREZ SANZ, El Jurado: aproximación a su sentido histórico y actual, pág. 68. Tal y como se sucedieron los hechos y las normas parece difícil de creer que en la reunión estuviesen representados todos los partidos políticos.

Redur 4 / 2006 
soberanía nacional, el sufragio universal, los derechos y libertades, la unidad de legislación y de fueros y la institución del Jurado ${ }^{28}$.

Fueron convocadas y elegidas Cortes con el objeto primordial de elaborar una nueva Constitución, pero además, y como ocurriera en Cádiz, las Cortes desarrollaron una profusa labor legislativa, que en cierto modo fue precedente, guía y complemento del texto constitucional.

El Proyecto de Constitución, por lo que a nuestro tema interesa, recogía en su artículo 93: «Se establecerá el juicio por Jurados para todos los delitos políticos y para los comunes que determine la Ley. La Ley determinará también las condiciones necesarias para desempeñar el cargo de Jurado». Al Proyecto se presentó la enmienda del diputado Sr. Rodríguez Pinilla, en el sentido que el Jurado fuera competente en toda clase de delitos, pero sobre todo, y quizá ante el temor de que ocurriera como en otras ocasiones y fuera aplazado, que el Jurado entrara en vigor de inmediato, dada la «importancia que tiene esta alta y nueva institución del Jurado» ${ }^{29}$.

La institución no era nueva ni tampoco era nueva la petición de que se contemplara el Jurado para toda clase de delitos, no solamente para los delitos de imprenta, como había ocurrido hasta entonces, pues ya se recogía en estos términos en la constitución de i837. Si bien recordemos que en aquella ocasión se pospuso a que las Cortes lo establecieran. La enmienda no fue aprobada y el artículo 93 de la Constitución recogió lo contenido en el Proyecto de manera literal $^{30}$. Si bien es significativo que ahora no se pospone a lo que decidan otras Cortes, sino que el artículo es imperativo en su redacción: «Se establecerá el juicio por Jurados...». Frente a lo que temiera el parlamentario, el mandato constitucional tuvo efecto y fruto del mismo fueron importantísimas Leyes, a saber, La Ley Provisional sobre Organización del Poder Judicial, de I5 de septiembre de I870; la Ley adicional a la Orgánica del Poder Judicial de I4 oct de I882, que completaba la anterior; y por último la Ley de Procedimiento Criminal de i872.

El artículo 276 de la primera estipulaba la intervención del Jurado en los procesos más graves, de manera que debía intervenir, junto a las Salas de lo criminal de las Audiencias, en el conocimiento de las causas por delitos con pena superior a presidio mayor así como en los de lesa majestad, rebelión y sedición. Son los más graves pero también los menos frecuentes. Ese artículo viene completado por la disposición transitoria $3^{a}$ que hacía hincapié en la necesidad de reformar los procedimientos criminales en orden a que la intervención del Jurado sirviera para satisfacer las exigencias de justicia ${ }^{3 \mathrm{I}}$.

El ministro de Gracia y Justicia, Eugenio Montero Ríos, en el discurso que pronunció en la apertura de los tribunales ese año, tuvo buen cuidado de aparecer como moderador y así se refería al Jurado como un tribunal complementario, que en ningún momento debía verse como rival de los tribunales de Derecho sino que venía a cubrir una faceta diferente, pues afirmando la plena e indudable preparación e idoneidad para cumplir su cometido de estos, el Jurado representaba una visión quizá más sencilla y más práctica,

${ }^{28}$ TORRES DEL MorAl, A., Constitucionalismo histórico español, pág. 99. Madrid I999.

${ }^{29}$ VilatA MENADES, Sobre el Jurado: un análisis desde una perspectiva distinta, pág. 76.

$30 \mathrm{Al}$ poco de aprobarse la Constitución, el mismo diputado presentó a la Cámara el primer Proyecto de Ley reguladora de la institución. Ibídem, 77.

${ }^{3}$ I Dicha disposición transitoria establecía que el Gobierno había de proceder a reformar los procedimientos criminales sujetándose a las siguientes reglas: « ... f. Procedimiento para el castigo de los delitos en que haya de intervenir el Jurado con las Audiencias, ... i. Organización del Jurado de modo que por sus condiciones de capacidad asegurada por el derecho de recusación satisfaga las exigencias de justicia». Ídem. 
de tal modo que no se podía desconocer «la plena aptitud para apreciar aquéllos (refiriéndose a los hechos) que tiene la institución formada por individuos que van a sentarse al Tribunal con una suma de elementos de acierto que no pueden frecuentemente reunirse en un Juez que, atento al estudio del Derecho, desciende rara vez a las pequeñas realidades de la vida» ${ }^{32}$.

Respecto a quienes podían formar parte del Jurado, la regulación que se establece por la Ley es importantísima por cuanto se trataba de la primera ocasión en que se contemplaba la participación ciudadana con carácter general. Recordemos que anteriormente habían primado la propiedad y la capacidad. La Ley de I870 indudablemente significaba un avance en muchos campos, y también en lo referente al Jurado. Sin embargo no se consideró suficiente, por ello en julio de 1872 , Montero Ríos se dirigía al monarca en estos términos:

«SEÑOR: entre las reformas que se han llevado a efecto en España desde que fue establecido el Gobierno Constitucional, figuran en lugar preferente las que se refieren a la codificación civil y criminal y organización de los tribunales... En la actualidad se hallan pendientes varias reformas cuya necesidad es cada día más notoria, descollando entre ellas la Institución del Jurado, que es de urgencia suma, puesto que tiende a dar aplicación práctica a uno de los más trascendentales preceptos de la Constitución del Estado.

El gobierno de V. M. se ha comprometido solemnemente a llenar en un breve plazo el vacío que ocasiona la falta de esta institución, tantas veces prometida y siempre relegada á un lamentable olvido. El ministro que suscribe, deseoso de cumplir puntualmente ese compromiso, ha formado un proyecto de procedimiento criminal con la organización del Jurado, pero cree que para conseguir el inmediato planteamiento de aquella institución y para completar el sistema general de reformas há tiempo iniciado, y fatalmente interrumpido con grave perjuicio para la administración de justicia, es necesario cambiar en sus fundamentos la manera de ser de esos cuerpos científicos que concurren con sus luces y su saber al desarrollo y planteamiento de las reformas que el gobierno se propone». Madrid, II de julio de I $872^{33}$. Gaceta de Madrid de I6 de julio de I872.

Esta petición dio relativos frutos en lo que al Jurado se refiere, que vendrán representados por el $R$. D. de 22 de diciembre de $I 872$ en que al promulgarse la Ley Provisional de Enjuiciamiento Criminal, se regulaba el juicio oral ante el tribunal popular, y por la $R$. O. de 28 de diciembre, que regulaba su funcionamiento ${ }^{34}$.

Voy a extenderme un poco en la Ley Provisional de Enjuiciamiento Criminal, porque además de ser la primera gran Ley que se ocupa del Jurado, tendrá gran influencia en la Ley del Jurado de I888. Le da curso legal el Real Decreto de 22 de diciembre de I872, publicado el 24, que dispone «la publicación de la Ley Provisional de Enjuiciamiento

\footnotetext{
${ }^{32}$ Ibídem, 78

33 Propone Montero Ríos al monarca, y este acepta, nombrar una comisión para cada asunto a reformar, de manera que con la misma fecha, Amadeo de Saboya, y respecto a lo que a nosotros nos interesa, decreta el nombramiento de una comisión especial «para la formación de un proyecto de Ley de Enjuiciamiento Criminal y Organización del Jurado» que estaría compuesta por el mismo ministro de Gracia y Justicia como presidente, Nicolás María Rivero como vicepresidente y por los vocales Laureano Figuerola, Sebastián González Nandín, Álvaro Gil Sanz, Manuel Vicente García, José Garnica y Vicente Hernández de la Rua. Gaceta de Madrid de I6 de julio de I872. R. D. de II de julio, publicado el I6. C.L, tomo CIX, págs. 6i y 62.

34 «Real Orden encareciendo a las autoridades judiciales y a los funcionarios del Ministerio Fiscal la adopción inmediata de las disposiciones que crean convenientes para el planteamiento de la nueva Ley de Enjuiciamiento criminal, y muy particularmente en la parte referente al Jurado». Gracia y Justicia, 28 Diciembre: publicada en 30. C. L., tomo CIX, pág. IIoı.
}

Redur 4 / 2006 
Criminal y que empiece a regir desde el i5 de enero próximo en la Península è Islas Baleares y Canarias» ${ }^{35}$.

El título IV de la Ley comienza a ocuparse del Jurado: DEL JUICIO ORAL ANTE EL JURADO. Su Capítulo I: de la composición del tribunal del Jurado, recoge los capítulos 658 a 66o. El primero de los cuales establece que: «El tribunal del Jurado se compondrá de I2 Jurados y de 3 Magistrados».

El capítulo II: de la competencia del Tribunal del Jurado, recoge en el artículo 66I los delitos en los que podrá intervenir el mismo y establece, además de los delitos con pena superior a presidio mayor y otros delitos especificados en el Código Penal, los delitos cometidos por medio de la imprenta u otro medio mecánico de publicación. Hasta aquí la Ley es heredera de la legislación precedente. Lo novedoso es la regulación que establece de la competencia del tribunal popular en los delitos definidos y penados en la Ley Electoral. El capítulo comprende asimismo los artículos 662 y $663^{36}$.

El capítulo III dispone en los artículos 664 y 665 las circunstancias necesarias para ser Jurado, a saber: Ser español, mayor de 30 años, en el pleno goce de los derechos políticos y civiles. Además de saber leer y escribir, tener la cualidad de vecino en el término municipal respectivo y de hallarse incluido como cabeza de familia, con casa abierta, en las listas que deberán formarse en cada uno de los términos municipales. O sin ser cabeza de familia siempre que se reúnan los requisitos fijados en el artículo $665^{37}$.

${ }^{35}$ C.L., tomo CIX, pág. 889. Las reglas $6^{a}$ y $7^{a}$ del Decreto hacían referencia al Jurado.

Regla 6a: «Mientras que no se establezcan los Tribunales de partido, los recursos de alzada que se interpongan ... y las terceras listas del Jurado se formarán y rectificarán por las Salas de lo criminal de las Audiencias. Estos incluirán en ellas cien Jurados por cada partido judicial, eligiéndolos entre las capacidades y cabezas de familia segun la proporcion establecida en el art. 692.

Regla $7^{\text {a: }}$ La formación de listas de Jurados que por primera vez habrá de hacerse se acomodará a lo dispuesto ...».

${ }^{36}$ C.L. tomo CIX, pág. 99I

37 Podían ser Jurados, sin ser cabeza de familia, los españoles mayores de edad incluidos en las listas de capacidades que se formarán en cada término municipal. Se consideraba como capacidad, «el que tuviere un título profesional o hubiere desempeñado algún cargo con la categoría de Jefe de negociado de Administración». El artículo 666 recogía las incapacidades para ser Jurado, estableciendo hasta seis condiciones. C.L. tomo CIX, pág. 992. Por su parte los artículos 667, 68 y 69 fijan las incompatibilidades y el 670 los que pueden excusarse del desempeño del cargo.

El Capítulo IV: de la formación de las listas del Jurado, recoge los artículos. 67I a 697

El Capítulo V: de las diligencias preparatorias para la Constitución del Tribunal del Jurado, comprende los artículos 698 a 7 I5

El Capítulo VI: de la confesión de los acusados y del modo de proponer y preparar las pruebas, contiene los artículos 7i6 a 723 .

El Capítulo VII: de la recusación de los Jurados recoge los artículos 724 a 732

El Capítulo VIII: del juramento de los Jurados, dispone cómo, cuándo y ante quien se ha de prestar juramento en los artículos 733 y 734.

El Capítulo IX: de las pruebas, de la acusación y de la defensa, engloba los artículos 735 a 740.

El Capítulo X: de las preguntas que han de ser contestadas en el veredicto, y de las deliberaciones y decisiones del Jurado y del Tribunal de derecho, consta de los artículos 74I a 788.

El Capítulo XI: de los recursos de reforma del veredicto y de revista de la causa por nuevo Jurado, se extiende desde el artículo. 779 al 785 . 
La ideología democrática imperante se pone de manifiesto en distintos lugares de la Ley, pero sobre todo porque considera que el ser Jurado, que el participar en la administración de justicia es un verdadero derecho de los españoles, aunque al exigir saber leer y escribir para formar parte del Jurado se limitaba considerablemente las posibilidades dados los bajos niveles de alfabetización de la época.

Agustín Pérez-Cruz ${ }^{38}$ ha destacado que la Ley incurría en graves defectos en lo que se refiere a la regulación, y sobre todo, al funcionamiento del Jurado, pero creo que el esfuerzo fue grande y que merece la pena destacarse por lo que supuso de reconocimiento y organización de la institución fuera de los delitos de imprenta, lo que venía a reconocerle una nueva dimensión. Además la inestabilidad de los tiempos llevará a que no tenga demasiada virtualidad pues la renuncia de Amadeo de Saboya, la proclamación de la Primera República, la elaboración de una nueva Constitución y finalmente el golpe de Estado de Martínez Campos en Sagunto, darán al traste con el reconocimiento del Jurado apenas dos años después. Por otro lado, y según el expediente que se instruyó por el ministerio de Gracia y Justicia en I874, la institución no gozaba de buena salud, ya que: «resultó, entre otras cosas, que el ser Juez de Hecho se miraba, no como honrosa función pública, sino como pesada carga de la cual procuraban libertarse cuantos tenían excusa legal para oponer, llegando muchos al extremo de consentir en ser procesados por no desempeñar funciones judiciales, prefiriendo el papel de reo al de Juez; resultando casi siempre invencible la resistencia de Jurados y testigos para acudir al tribunal» ${ }^{39}$.

Proclamada la República, se presentó a discusión un Proyecto de Constitución, en julio de 1873 , que no vería la luz pero que interesa por la concepción que tiene sobre la institución del Jurado. La considera de tal importancia que se ocupa de ella en el título preliminar, reconociéndola como derecho natural, al mismo nivel que el derecho a la vida, a la seguridad o a la dignidad. Dice el título preliminar: «Toda persona encuentra asegurados en la República, sin que ningún poder tenga facultades para cohibirlos, ni ley ninguna autoridad para mermarlos, todos los derechos naturales.

$\mathrm{I}^{\mathrm{o}}$. El derecho a la vida, y a la seguridad, y a la dignidad de la vida.

$2^{\circ}$. El derecho al libre ejercicio de su pensamiento y a la libre expresión de su, sin facultad de vinculación ni amortización. ...

$8^{\circ}$. El derecho a ser jurado y a ser juzgado por los jurados: el derecho a la defensa libérrima en juicio; el derecho, en caso de caer en culpa o delito, a la corrección y a la purificación por medio de la pena.

Estos derechos son anteriores y superiores a toda legislación positiva».

Su artículo 48, en esa línea de dar máxima relevancia al Jurado, lo sitúa al mismo nivel que los tribunales ordinarios, así dice: «El Poder judicial será ejercido por Jurados y Jueces, cuyo nombramiento no dependerá jamás de los otros Poderes públicos».

Por último, el título X en su apartado 4 establece el Jurado para toda clase de delitos. En cada Municipio habrá un Tribunal nombrado directamente por el pueblo y encargado de entender en la corrección de las faltas, juicios verbales y actos de conciliación.

Los Títulos V «disposiciones generales a los dos títulos anteriores» y VI, artículo 806 se ocupan asimismo del Jurado. Por último, los artículos 809 a 8 II recogen las últimas disposiciones sobre el tema.

${ }^{38}$ La participación popular en la Administración de Justicia. El Tribunal del Jurado, Madrid, i992.

${ }^{39}$ Vilata Menades, Sobre el Jurado: un análisis desde una perspectiva distinta, pág. 78 
El régimen republicano tuvo una vida exigua y el Proyecto de Constitución nunca vio la luz como texto fundamental por lo que las disposiciones relativas al Jurado, que en algunos casos rayaban en la utopía, desaparecieron con ellos.

\section{Ascenso y caída de la institución del Jurado.}

La solución, como ya fuera habitual en nuestra historia, la proporcionó un golpe militar que terminaba con una nueva forma de gobierno y reintroducía una dinastía. Martínez Campos encabezó el levantamiento en Sagunto en virtud del cual se vuelve a la monarquía como forma de gobierno, y se restaura en el trono a la dinastía borbónica en la persona de don Alfonso XII.

Casi inmediatamente, el 3 de enero de I875, un Decreto del Ministro de Gracia y Justicia, Francisco Cárdenas, suspendía la vigencia de la parte de la Ley Provisional de Enjuiciamiento Criminal relativa al Jurado, y al juicio oral y público ante los tribunales de derecho. En su preámbulo se señalaban las graves disfunciones detectadas durante los meses de vigencia de la Ley, haciendo hincapié en que se daban resoluciones benévolas sin que estuvieran totalmente justificadas ${ }^{40}$.

Fruto de esa ideología ya latente en el ministerio de Regencia, la Constitución de I876 no se refiere en ningún momento al Jurado. Para ella la institución no existe. El título $\mathrm{X}$, que se ocupa de la administración de justicia recoge escuetamente lo relativo a los tribunales, pero sin que en ninguno de sus artículos haga referencia a la institución, como hemos señalado ${ }^{4}$. Si bien, y aunque parezca una paradoja, es bajo esta Constitución, cuando el Jurado encontrará por fin su formulación más adecuada, su reconocimiento amplio, y su mayor vigencia, gracias a la tan ansiada por algunos Ley de i888.

Desde la suspensión del Jurado en I875 hasta la reinstauración en I888, se vivió un clima de abundantes disputas entre los partidarios de la institución y los detractores de la misma. El 9 de enero de 1883 una crisis de gobierno ponía la cartera de Gracia y Justicia en manos de Vicente Romero Girón ${ }^{42}$, en sustitución de Alonso Martínez. Romero, gran partidario del Jurado como había demostrado en sus intervenciones parlamentarias, presentará un Proyecto de Ley para el establecimiento del Tribunal del Jurado en materia criminal tan solo un mes después de tomar posesión como ministro. Crisis en el gobierno, la sustitución de Romero en la cartera de Gracia y Justicia, y otros acontecimientos políticos, llevaron a que el Proyecto se quedase simplemente en eso.

40 Ibídem, págs. 80 y 8I. Señala este autor como ya desde el 3 de septiembre de I874, cuando se forma el Gobierno, se tenía preparado un borrador de Decreto acordando la suspensión de la Institución que en su preámbulo decía: «El Ministerio-Regencia que se ha propuesto ceñirse a mantener el orden social y a satisfacer las más apremiantes necesidades del servicio público... se ve en la precisión de poner la mano en un punto muy importante del derecho procesal, por exigirlo así la suma urgencia de la medida que es indispensable dictar». La férrea mano de Cánovas del Castillo supo poner orden, y en su pragmatismo, y buscando lo posible en el gobierno, no permitió «veleidades» democráticas que alterasen su programa.

${ }^{4 \mathrm{I}}$ Tampoco la Ley de Enjuiciamiento Criminal de I882 hace referencia alguna al Jurado. En la exposición de motivos que presenta el Ministro de Gracia y Justicia, Alonso Martínez, del $R$.D. de I4 de septiembre de I882 aprobando el Proyecto de Código de Enjuiciamiento Criminal, se señalan los errores que se quieren corregir con él frente al vigente, como la excesiva duración del sumario y la indefensión del reo, y cómo la nueva Ley pretende sobre todo sustituir el procedimiento escrito, secreto e inquisitorial por un juicio oral y público, pero en ningún momento se hace referencia al Jurado.

$4^{2}$ Romero Girón será ministro de Gracia y Justicia hasta el I3 de Octubre de i883. 
Consecuencia del pacto de Reforma Constitucional, que propicia el reforzamiento del Partido Liberal y recupera en cierto modo planteamientos de I869, será el anuncio que el 8 de mayo de i886 realizará el presidente del gobierno, Práxedes Mateo Sagasta, del propósito de presentar un Proyecto de Ley del Jurado. El propósito iba en firme pues tan sólo dos días después, y con ocasión del Mensaje de la Corona en el acto de apertura de las Cortes, se reiteró la intención de elaborarlo ${ }^{43}$.

El Proyecto corrió a cargo de Manuel Alonso Martínez, que había recuperado la cartera de Gracia y Justicia el 27 de noviembre de $1885,{ }^{44}$ y para su elaboración se tuvieron en cuenta la Ley de Enjuiciamiento Criminal de I872, la opinión manifestada en diferentes informes tanto de las Audiencias como de las Universidades, Colegios de Abogados y otras instituciones. Así como las Leyes que sobre la institución existían en otros países. Además dejaron su impronta en la Ley, por una parte, el Proyecto que había elaborado y presentado el anterior ministro de Gracia y Justicia, Romero Girón, y por otra la actuación del mismo ministro, Alonso Martínez, en especial en cuanto al entronque del Proyecto con la Ley de Enjuiciamiento Criminal de i882, que era la vigente y a la que tuvo que ajustarse en sus aspectos procesales ${ }^{45}$.

El 28 de noviembre de 1886 fue presentado por fin en el Congreso un Proyecto de Ley del Jurado por el ministro del ramo, Manuel Alonso Martínez. Publicado en la Gaceta de 2 diciembre, contenía I29 artículos, una disposición especial y 3 transitorias.

En el preámbulo hace notar el ministro que presenta el Proyecto de Ley porque cree que es el momento oportuno y que la intervención del pueblo en la administración de Justicia servirá para mejorarla, que es lo que en definitiva pretende ${ }^{46}$. Por fin se considera que España está preparada para esta institución.

El 6 de diciembre se nombró la Comisión que habría de dictaminar sobre el Proyecto presentado. La Comisión estaba presidida por Antonio Maura y el secretario era Juan Rosell ${ }^{47}$. La Comisión presentó sus conclusiones en el Congreso el to de marzo de I887, con leves modificaciones respecto al Proyecto presentado. Teniendo como base dicho Proyecto y dichas conclusiones, el 2I de abril se iniciaron las discusiones en la sede de la Cámara Baja. El I4 de mayo la Ley del Jurado fue aprobada en el Congreso con 2I7 votos a favor, 49 en contra y el liberal Espinosa representó la abstención ${ }^{48}$.

No me extiendo sobre las diferentes intervenciones, aportaciones, etc. pero si señalar, por su significación, la justificación que tuvo que hacer de su cambiante postura respecto al Jurado el ministro Alonso Martínez cuando el diputado Alejandro Pidal y Mon le

${ }^{43}$ Vilata MenadeS, Sobre el Jurado: un análisis desde una perspectiva distinta, pág. 82.

${ }^{44}$ Manuel Alonso Martínez estuvo en el ministerio de Gracia y Justicia hasta el I4 de Junio de I888, y desde esa fecha hasta el in de diciembre, siempre estando en la presidencia del Gobierno Sagasta.

${ }^{45}$ GUTIÉRREZ SANZ, El Jurado: aproximación a su sentido histórico y actual, pág. 76

${ }^{4}$ Ibídem, 7I

47 La Comisión se completaba con los vocales, Francisco de Asís Pacheco, Antonio García Alix, Enrique Santana, Félix García Gómez de la Serna y Luis Díaz Moreu.

${ }^{4}$ Rosa Gutiérrez recoge en las páginas $7 \mathrm{I}-76$ los datos más interesantes de las discusiones parlamentarias tanto en el Congreso como en el Senado. De ellas he tomado las escuetas referencias al proceso.

La prensa se hizo eco de las posturas a favor y en contra del Jurado, alimentando el interés por el tema.

Redur 4/2006 
recriminó por ello. El ministro aludió a «razones de política y servicio al país y a la Corona para aceptar un Jurado que antes le parecía inaceptable».

Posteriormente la Ley se remitió al Senado donde siguió el trámite parlamentario, con interesantes intervenciones a favor y en contra del Jurado que concluyeron con algunos cambios en la Ley presentada y su aprobación en el Senado con I22 votos a favor y 52 en contra. Era el 24 de marzo de i888. Remitida de nuevo al Congreso, la Ley fue aprobada el día 27 por I9o votos a favor y 26 en contra. Buscando la pronta puesta en marcha de la Ley, la Reina firmó un Decreto, en nombre de su hijo Alfonso XIII, el 20 de abril, a fin de iniciar el proceso de la formación y funcionamiento de la institución del Jurado. Tal y como se recogía en el Decreto, el I de enero del año siguiente. La Ley entró en vigor y previó las primeras sesiones para el mes de marzo.

«Ley de 20 de abril de I888. Estableciendo el juicio por Jurados para los delitos que se expresan, y determinando la constitución y competencia del Tribunal popular, el procedimiento que ha de seguirse en los juicios de que conozca y los recursos contra sus veredictos». Fue publicada en la Gaceta del 24 de abril y se incluyeron rectificaciones en la Gaceta del día siguiente. La Ley comprendía I22 artículos, 3 disposiciones especiales y un artículo adicional, estructurados en I8 capítulos, lo que representa para algunos una extensión excesiva, que señalan como inconveniente o defecto de la misma ${ }^{49}$.

Establece la Ley que el Tribunal del Jurado se compondrá de doce Jurados con dos suplentes, y tres magistrados, y será competente en el conocimiento de los delitos que especifica el artículo 4 incluyéndose no sólo los consumados sino también los frustrados y tentativas, así como la proposición y conspiración si estuvieran penadas en el Código. Igualmente se extiende la competencia a cómplices y encubridores.

Los requisitos para ser jurado son similares a los establecidos por la Ley de I872, siendo igualmente obligatorio el ejercicio de esa función, recogiendo la Ley las excepciones, incompatibilidades, recusaciones, formación de listas, etc. Acoge asimismo el juramento que han de prestar los catorce miembros del Jurado, cómo ha de discurrir el juicio, y cómo han de deliberar y fallar, estableciendo que «la mayoría absoluta de votos formará veredicto» (Artículo 85). Se regula a continuación el juicio de derecho y los recursos posibles.

Según Real Decreto de la misma fecha, la Junta que recogía el artículo i6 de la Ley habría de reunirse la primera quincena de junio, y el Jurado comenzaría a conocer de las causas de su competencia por delitos cometidos a partir del inicio del año siguiente ${ }^{50}$.

49 AlCAlÁ Zamora y CASTillo, «A propósito del Jurado», Separata del Boletín del Ilustre Colegio de Abogados de Madrid, 3/1980, pág. I2, citado por GUTIÉRREZ SANZ, El Jurado: aproximación a su sentido histórico y actual, pág. 77.

${ }^{50}$ Algunas disposiciones posteriores vinieron a aclarar y/o completar la Ley. Así el 23 de junio se da una Ley sobre constitución de los Tribunales que han de conocer de las causas no sometidas al Jurado en las Islas Baleares y Canarias.

Una R. O. de 26 de junio de I888, dirigida al presidente de la Audiencia Territorial de Burgos, le indicaba que transmitiese a los jueces municipales y de instrucción que examinasen cuidadosamente las excusas presentadas para no servir el cargo de Jurado al objeto de que no se burlase la Ley pero que tampoco la exigencia fuera desmedida originando quejas y reclamaciones que entorpecían la buena marcha de la institución. La existencia de esta R. O. hace suponer que se habían producido inconvenientes graves en la provincia.

Un R. D. de I7 de junio de I889 regula las dietas de los jurados y magistrados, estableciendo un máximo de io pesetas para los jurados y las cantidades que establecía la Ley Orgánica del Poder Judicial para los magistrados.

Redur 4 / 2006 
Para conocer la efectividad de la Ley de 20 de abril de 1888 , un Real Decreto de 24 de septiembre de 1889 estableció la obligatoriedad de elaborar una memoria anual sobre el funcionamiento del Jurado, que sería realizada por los presidentes y fiscales de las Audiencias Territoriales y de lo Criminal, y que sería enviada al Ministerio de Gracia y Justicia dentro del mes de enero de cada año. La mayor parte de estos informes que se conocen ponen de manifiesto múltiples deficiencias y dificultades en el funcionamiento del sistema establecido por dicha Ley. En el que se elabora por la Fiscalía del Tribunal Supremo ese mismo año de 1889 ya se aboga por una reforma de la norma. Los informes de los años siguientes no son mejores. Paulatinamente se ponen de relieve los defectos y sobre todo los problemas causados porque contrariamente a lo que creían sus más convencidos defensores, el formar parte del Jurado se ve como una pesada carga, de manera que en muchas ocasiones son los más indefensos y los menos preparados, los que componen los Jurados, y ello porque no pueden o no saben cómo librarse ${ }^{5 \mathrm{I}}$. Quizá la situación viene expresada con gran crudeza en la memoria de 1895 cuando se dice que la misión de Jurado no se considera que ennoblezca y honre sino que es rechazada abiertamente por los que tienen que ejercerla, y de hecho, es ejercida por los más ignorantes, miserables y desvalidos. Los informes de los años siguientes recogen testimonios similares y se insiste en la necesidad de una profunda reforma.

No se produjo la tan solicitada reforma ${ }^{52}$ pero los acontecimientos políticos que se desarrollaron en España llevarían poco a poco a la extinción de la institución. Sendos reales Decretos de I907 y I920 suspendieron el tribunal del Jurado para ciertos delitos y en ciertos lugares, Barcelona y Gerona. Pero el fin del Jurado vino como consecuencia de la sublevación y el golpe de Estado subsiguiente del Capitán General de Cataluña, Miguel Primo de Rivera, el I3 de septiembre de I923. La situación era complicada tanto a nivel político como social, económico, militar... Maura había prevenido al Rey de que no era aconsejable entrar en una espiral represiva o en un sistema autoritario, y mucho menos pensar en un golpe de estado. El día siguiente al pronunciamiento militar, el i4 de septiembre, el gobierno legítimo había pedido al Rey la destitución inmediata de los generales sublevados, tanto de José Sanjurjo como de Miguel Primo de Rivera, y la convocatoria de las Cortes, pero el monarca hizo caso omiso de los consejos, apoyó abiertamente el golpe y nombró Presidente a Primo de Rivera. Se sustituyó el Gobierno por un Directorio Militar, integrado por nueve generales y un almirante, se suspendió la Constitución, se disolvieron los Ayuntamientos, se prohibieron los partidos políticos y se declaró el estado de excepción. Dentro de esta dinámica represiva extrema, un Real Decreto del día 2I de ese mismo mes de septiembre suspendía la institución del Jurado en todo el territorio nacional.

El Jurado, fruto de las ideas liberales y democráticas, sucumbía como aquellas, bajo el sable de la represión, el autoritarismo y la dictadura, aunque eso si, como mantenían los sublevados, todo ello era para salvar a España.

\footnotetext{
${ }^{51}$ En este punto, el problema era similar a lo que había ocurrido con la Ley de i872 y que recogía el informe de 1874 .

$5^{2}$ Pequeños cambios fueron introducidos por la Ley de Explosivos, de I894, y por Ley de enero de I900 que exceptuaba del conocimiento del Jurado algunos delitos contra las autoridades civiles, militares y eclesiásticas, así como aquellos que supusieran un ataque a la integridad de la nación.
}

Redur 4 / 2006 